\title{
Population Mobility Based on Social Integrity Factors
}

\author{
Triwahyudianto \\ Students of Doctoral Program \\ State University of Malang \\ Malang, Indonesia \\ Coresponding email: u.diant@yahoo.com
}

Suwito

Students of Doctoral Program

State University of Malang

Malang, Indonesia

\begin{abstract}
The approach of population mobility study from social integrity's point of view begin from assumption that an individual who has less integrity to his neighborhood can give a forcing power to the different patterns and numbers of the population mobility. The objective of this study is to examine the different between the pattern and the degree of population mobility based on social integrity factors, i.e. age, gender, marital status, family size, educational level, and income. The research design used is expose facto casual comparative, with sample of 200 residences in Tureen, Malang Regency. Data are collected by observation, questioner, interview, and documentation. From a statistics research using variant analysis (Anova) found that there is a distinction in the pattern of population mobility due to the factors of age, family size, education, and income. T-test analysis also found that there is a distinction in the level of population mobility due to age, family size, education, and income. On the other hand, the degree and the pattern of population mobility are different based on gender and marital status by chi-square analysis.
\end{abstract}

Keywords-Population mobility, social integrity factors

\section{INTRODUCTION}

History of the world population mobility is in line with the process of human civilization in order to maintain and acquire a decent life. The description of the phenomenon of population mobility can be seen since humans are still in shifting cultivation level (shifting land system). In some local terms, it is called taungya (Burma); caingin (Thailand); Milpa (Mesiko); chitemene (Africa) (Bintarto, 1977: 72).

After man was in advance stage cultivator, that was after the man knows intensive farming systems, the mobility of the population began to decline. Yet, the current mobility began to strengthen in line with the reduction in the carrying capacity of natural resources, especially agriculture as a result of high population growth. Starting from this phenomenon Mantra (1985: 15) said that the migration will take place until the end of time.
Ever since, Indonesia's population may move from one area to another, either by themselves or in groups. Such movements generally to find a job or continuing education away from home or homeland. The pattern of displacement is called "merantau" (wandering).

Generally, wander we can be understood as a form of population movements, where someone left his hometown with the expectations of the areas which it is intended. There are two patterns of displaced living in Indonesia are called "pindah" (moving) and "merantau" (wandering). Moving is interpreted as changing domicile to settle for a long time. Wandering is changing domicile for work or trade usually without bringing the family.

According to Naim (1974: 18), wandering consists of six main elements, namely (1) leaving home; (2) for a short time or a long time; (3) voluntarily; (4) aiming at making a living; (5) desiring to return to hometown; (6) as habitual patterns of society culturally.

On the other hand Sahur (1988: 15-16) divides wandering into 3 types: (1) the type of seasonal wandering that is usually done in a particular season; (2) the type of non-seasonal wandering that is not seasonally done at any time up to the person who wanted to do so in the short-term (one week to six months) and long-term (six months to one year) and (3) the type of permanent wandering that one spent unlimited time there and rarely return home unless there is something special and generally has brought the family: his wife and children.

The process of modernization has accelerated the occurrence and expanding the number of people who wander with the aim of not only looking for a job or trade but also to achieve other goals. Background of wandering or migration is increasingly diverse, not only due to economic factors but socio-cultural, ecological and political factors. 
The process of modernization not only bring positive but also negative impacts. In general, the process of modernization became one of the main causes of mobility. The result of modernization here means the change that occurred simultaneously with the modernization efforts that theoretically includes the six major fields, namely: demographics, a system of stratification, demand, education, family systems and value systems.

The unwanted but unavoidable result of modernization, the imbalance of social, economic and technological inequality, has participated spur migration of the population. Inequality, especially in the field of economy, has resulted in the central region and the edge areas that can form multiple poles of growth, it is possible there is an imbalance of regional or differences between one region to another, giving rise to the movement or the movement of people from the center edge to the center and allowing the opposite. Thus, the movement of the population can be seen as a response to the widely structural changes in a society. Based on this perspective, it's explained that the movement of the population needs to be sought in the processes that shape spatial inequity opportunity (Prabatmodjo, 1992: 45)

In general, the study of population mobility in Indonesia suppress the permanent population mobility, those are the interprovincial migration, urbanization, and transmigration. Some of the studies conducted before 1970 among others by: Pelzer (1945), Gentlemen (1955), Utomo (1957), mc Nicoll (1968).

Development activities may affect the pattern and rate of population mobility. Yet, population mobility affects development and the process of social and economic change. In its turn, there will also be a variety of organizational and structural changes that results in increasing of population mobility. Development activities in the field of agriculture in rural areas in the short term can control the rate of mobility of the population outside the village, but in the long-term mobility to residents outside the village tends to increase.

Therefore, this study was conducted to study the behavior of either settled or temporarily population mobility on the environment, especially the farmers in rural areas, so it will get unanimous knowledge about the phenomenon of population mobility.

In addition, it is also realized how important the study of population mobility is associated with changes in socioeconomic population. Without looking this connection, the mobility study population do not have much significance for the development of the science community development itself. Besides, the study of the mobility of the population needs to be linked to the business development efforts (national, regional and rural) that's increasing these days. Finally, it's studied how the extended development activities affect the patterns and degree of population mobility and conversely, how the behavior of population mobility activities affects development activities.

Patterns and levels of population mobility, in particular, happening to farmers have close relation to declining percentage of households landowners and the percentage of households landowner other people, that is believed to be caused by a perceived as a farmer that profits gained from trying to farm (among others is the urge of expanding business) become less attractive. The increase in household farmers who cultivate land owned by others allegedly getting higher is not because of the rent or for the results, but the relation of "ngedok" or "ngepak" that closer with the status of farm workers. The level of agricultural labor earning did not show an increase in the same period, despite increased rice yields per hectare per hour of work (Sayogya, 1981). Thus, the workers and peasants are less able to improve their lives meaningfully in the process of agricultural development today.

In the countryside, the opportunities to obtain employment that meet the sufficient need of a family is difficult to obtain. Average income is relatively low only around five thousand five hundred rupiahs to six thousand five hundred rupiahs per day. And that's still a gross wage for work of farm laborers, masons and others. In addition, they do not necessarily get to work every day. Sometimes they must be idle, waiting many days for the job. For example, in the working on the fields season, the farmers who work the land has agricultural land on the farm laborer. If this work is not labored by the owner, the farm laborers will be unemployed.

In addition, the emergence of new technologies that produce advanced equipment for agriculture such as rice harvester tools, hijackers machine, and others, results in the reduction in employment opportunities for farmers.

From the description of the phenomenon of population mobility explanation above, it can be said that as the cause of the mobility of the rural population is multidimensional and complex. However, it can be concluded that the cause of the mobility of the population are social and psychological factors which include: (1) the cultural factors that are desire to move since childhood; (2) the influence of others; (3) expanding the experience of life (4) low level of social integration. (Sahur, 1988; Leuwol, 1988; Daldjoeni, 1981; Schneider, 1985).

This study focuses on social integrity factors that lead to differences in the pattern and degree of mobility of the population, particularly the social integrity factor, namely: age, gender, education level and income level. Furthermore, these factors are used to give an explanation on the background of the mobility of the population. This template, modified in MS Word 2007 and saved as a "Word 97-2003 Document" for the PC, provides authors with most of the formatting specifications needed for preparing electronic versions of their papers. All standard paper components have been specified for three reasons: (1) ease of use when formatting individual papers, (2) automatic compliance to electronic requirements that facilitate the concurrent or later production of electronic products, and (3) conformity of style throughout conference proceedings. Margins, column widths, line spacing, and type styles are builtin; examples of the type styles are provided throughout this document and are identified in italic type, within parentheses, following the example. Some components, such as multi- 
leveled equations, graphics, and tables are not prescribed, although the various table text styles are provided. The formatter will need to create these components, incorporating the applicable criteria that follow.

\section{METHOD}

This study is survey research that is the research that took a sample of the population and the questionnaire as a data collection tool that principal (Singarimbun and Sofian Effendi, 1989: 3). The purpose of survey research is to provide an explanation for the relationship between variables through hypothesis testing. The design used in this study is the Ex Post Facto Data, which means data of a fact, indicating that the study was conducted after differences in the independent variables by natural developments (without manipulation).

Causal-comparative study design is used to distinguish the patterns and levels of population mobility seen from social integrity factor include: age, gender, marital status, family size, education, and income levels. The study population was 200 families in Turen of Malang Regency who work in agriculture which includes families who have land and lease land and have a family member who had migrated.

Data are collected by several techniques which include: observation (observation), interviews, questionnaires, and documentation. Some of these techniques are applied in accordance with the needs of research. The data are analyzed using Anova to determine differences in population mobility patterns seen on age, family size, education level and income. T-test analysis is used to determine differences in the level of population mobility visits of age, family size, education level and income level. Finally, Chi Square analysis is used to determine differences in patterns of population mobility views of sex, marital status and to determine the level of population mobility views of sex, marital status.

\section{FINDING AND DISCUSSION}

\section{A. The pattern of population mobility based on age}

The pattern of population mobility viewed in terms of age showed a difference. This means that in Turen Malang there are differences of population mobility patterns based on the age factor. It can be noted from the migration and commutation pattern. The average age to do commutation mobility is 24 years old, circulation mobility is 25 years old, while migration is 33 years old. Commutation and circulation patterns of population mobility almost have no difference from age point of view.

In general, this pattern of population mobility based on age shows the tendency that the older aged population do more migration than the commutation and circulation mobility. So the results of this study reinforce the theories that already exist that young people aged over have a high mobility when compared with the population of older age, in other words more young people doing commutation as well as the circulation of mobility.
On the other side, what corroborates the results of this research is reluctance to return to their hometown because they are generally already employed and working in a new place and have been fused to integrate with the environment where they live.

\section{B. The pattern of population mobility based on gender}

The pattern of population mobility viewed from gender factor has showed significant difference though the contingency coefficient is quite weak because it is below $50 \%$. Men do migration and circulation mobility more than women. Yet, commutation mobility is done by women more than men. This problem is related to the culture of the rural population that differentiates the status and role of women from men. Women serve as housewives and caregivers of children who carry the consequences of staying at home more than men. The shorter distance mobility can provide benefits, for example, the ability to take care of children or family in the homeland.

The low contingency coefficient (degree of relationship) between the mobility of the population and gender possibly is caused by of the influence of culture of the rural population related to the emancipation of women with access to the world of work and family responsibilities. However, these results still support existing theories that women have more mobility in a shorter distance than men.

\section{The pattern of population mobility based on marital status}

The pattern of population mobility from marital status point of view showed a significant difference, even though the contingency coefficient is quite weak because it is still below $50 \%$. Residents who are married do migration, circulation and commutation mobility more than unmarried. Unmarried population does circulation and commutation mobility but none do migration. This issue relates to the absence of intention to settle in the desired place. The low contingency coefficient between the mobility of the population and marital status is possibly caused by other variables those are more dominant on the pattern of population mobility.

However, the findings of this research are still reinforcing the existing theory that the marital status of the population, its mobility is lower than that of unmarried. Otherwise, unmarried population does more circulation and commutation than migration. The fact is supported by the reluctance of those who are married to do circulation and or commutation because they already had a family and occupation in a new place and they have been integrated with the environment they live.

\section{The pattern of population mobility based on family size}

The pattern of population mobility based on family size showed a difference. This means that there are differences of population mobility patterns from family size point of view. It can be seen that commutation and circulation mobility is done by four-member-family, while migration is done by fivemember-family. Commutation and circulation patterns showed 
almost no difference from an average number of family members, that is 4.19 and 4.21 .

In general, it can be said that the pattern of population mobility viewed in terms of the number of family members shows the tendency that the people who did the commutation and circulation is a resident of the number of family members between 3-4 people, while the number of family members 5-7 people did mobility migration.

In a relatively large family (5-7 people), there is a strong indication that the bonds in the family, for example: a sense bound by their parents or relatives do not become a barrier to the migration mobility. The disintegration of the family, among other things because of the seizure of economic assets the family or economic hardship due to a large number of family members, encourage the mobility of population migration patterns.

\section{E. The pattern of population mobility based on educational level}

In Turen Malang there are different patterns of population mobility from education level point of view. It can be seen that the migration patterns of commutation with the average level of educational mobility commutation value of 7.4 , while migration is 9 , and circulation is 8.1 .

In general, in terms of education level, people with higher education levels tends to do more migration than commutation and circulation patterns. So, the results of this study support or strengthen existing theories, that the higher the educational aspirations of rural people the more migration pattern done. The population with lower education level do more circulation and commutation rather than migration. The other side that corroborates the results of this research is a reluctance to return to their homeland because in general they have been able to integrate with their new neighborhood.

\section{F. The pattern of population mobility based on income}

The pattern of population mobility seen in terms of income showed a difference. People with average income of Rp290.127,00 do commutation mobility, whereas average income of Rp378.695,00 do migration, and average income of Rp337.500,00 do circulation mobility. The commutation and circulation pattern of population mobility almost have no difference.

In general, this pattern of population mobility viewed from income levels shows the tendency that people who have higher income do migration more than commutation and circulation mobility. So, the empirical result of this research strengthens existing theory that the lack of integration of someone with the neighborhood will encourage mobility in the form of migration.

\section{G. The level of population mobility based on age}

The level of mobility of the population viewed from age showed a significant difference. The result shows that either low or high level of population mobility is commonly done at the age of $15-40$ years old. While people older than 41 years old rarely do mobility.

The fact shows that age influence on the decision-making of population mobility. Older age groups do not do a lot of mobility because in general they have been integrated with its surroundings. A form of integration with the environment can be seen on the status and role in society.

\section{H. The level of population mobility based on gender}

There are different levels of population mobility from gender point of view. The research results that the low rate of population mobility prevalent in female population. Conversely high levels of population mobility are more common among male population.

Although there are differences in the level of mobility based on gender, but the level of relationship between the two is quite weak. This is possible because of the influence of the culture of the rural population that relates to the emancipation of women in accessing the world of work and family responsibilities.

\section{The level of population mobility based on marital status}

The level of mobility of the population visits of marital status showed a difference. The research that has been conducted shows that the low and high level of population mobility is commonly done by people whose status is married. The number of unmarried people doing high and low level of mobility is only a little.

Although there are different levels of population mobility when viewed from marital status, but the level of relationship between the two is quite weak. Weak level of relationship is possible because other variables are more dominant on the level of population mobility.

\section{J. The level of population mobility based on family size}

The level of mobility of the population seen from the number of family members showed a difference. This means that in Turen Malang there are different levels of population mobility based on the number of family members.

The level of population mobility seen from the number of family members showed that the low population mobility is more prevalent in families with four members. Conversely, high levels of population mobility are more prevalent in families with five members.

\section{K. The level of population mobility based on educational level}

The level of mobility of the population viewed from the level of education shows the differences. This means that in Turen Malang there are different levels of population mobility based on educational level.

The low of population mobility lower category is commonly done by people who only graduated from junior high school or elementary school. While the high mobility is much happening from people graduated ranging from senior high school to diploma. 


\section{The level of population based on income}

The level of mobility of the population viewed from the level of income showed a difference. This means that in Sub Turen Malang there are different levels of population mobility viewed from the level of income. The low level of population mobility occurs in many people with the level of income of Rp135.000,00-Rp290.000,00 (62.8\%). While high levels of population mobility occur in many people with the level of income of Rp375,000,00-Rp530.000,00(70.7\%).

So, the results of this study showed that the higher the income level the higher the level of mobility. These realities are relevant to the theory that the mobility out from the rural population is highest in the middle-income population groups to the top.

\section{IV.CONCLUSIONS AND SUGGESTIONS}

There are differences in the population mobility viewed in terms of age. The tendency shows that older people do more migration in pattern of commutation and circulation. This is in line with that proposed by Schneider Gold (1985: 76) that young people move more than the older people. There are differences of population mobility based on gender. Men do more mobility in pattern of circulation and migration than women who mostly do commutation mobility.

Differences appear in population mobility based on marital status. In general population mobility is carried out by people who are married more than unmarried. It is proved that migration patterns of population mobility done by the married people greater than the unmarried. However, examining further results that the unmarried people choose to do commutation or circulation mobility. The fact is in line with the theory that married population mobility is much lower than the unmarried.

Considering social integrity factors used to analyze population mobility in this research are still partial, this suggests that the next researchers willing to study similar topic do a holistic and comprehensive analysis to examine population mobility by associating subsocial integrity factor to clarify this phenomenon.

\section{REFERENCES}

[1] Sahur, A, 1988, "Merantau bagi Orang Pidi. Dalam Migrasi, Kolonisasi, Perubahan Sosial", Fikata, Jakarta.

[2] Bintarto, 1977, "Geografi social”, U.P, Spring, Yogyakarta.

[3] Mantra, I.B, 1985, "Pengantar Demografi”, Nurcahya, Yogyakarta.

[4] Naim, M., 1974. "Voluntary Migration in Indonesia", Working papers, department of sociology, University of Singapore.

[5] Prabatmodjo, H., 1992, "Prospek Migrasi ke Kota-Kota Menengah dan Kecil”, Journal of Urban and Regional Planning, no.3 triwulan 1 ITB Bandung. 